\title{
Inhibition of USP4 attenuates pathological scarring by downregulation of the TGF- $\beta$ /Smad signaling pathway
}

\author{
JIE ZHANG, SIJIA NA, SHUTING PAN, SANG LONG, YUQI XIN, QINGKUN JIANG, \\ ZHONGWEI LAI, JUNFENG YAN and ZHONGYI CAO
}

\begin{abstract}
Department of Oral and Maxillofacial Surgery, The First Affiliated Hospital of Nanchang University, Nanchang, Jiangxi 330006, P.R. China
\end{abstract}

Received October 16, 2018; Accepted April 17, 2019

DOI: $10.3892 / \mathrm{mmr} .2019 .10370$

\begin{abstract}
Pathological scarring is a result of the hypertrophy of scar tissue during tissue repair following trauma. The aim of the present study was to assess the effect of ubiquitin-specific protease 4 (USP4) silencing on pathological scarring, and to evaluate the mechanistic basis for the effect. An MTT assay was used to assess cell viability. Immunoprecipitation (IP) was used to determine ubiquitination levels of the TGF- $\beta$ receptor (T $\beta R$ )I and Smad7. Tumor formation was assessed by injecting keloid fibroblasts. Hematoxylin and eosin staining was used to detect pathological changes in tumor tissue. Reverse transcription quantitative polymerase chain reaction and western blot analysis assays were used to evaluate the expression levels of T $\beta$ RI and Smad7. Compared with the untreated control animals, cell viability and the expression of T $\beta$ RI and Smad7 increased significantly in animals treated with TGF- $\beta$. Short hairpin RNA for USP4 (shUSP4) decreased the cell viability of negative control cells, TGF- $\beta$-induced cellular proliferation, and the expression of T $\beta$ RI and Smad7. IP experiments indicated that the ubiquitination level of T $\beta$ RI was decreased following USP4 silencing. There was no remarkable difference in the structure of scar tissue among the various animal groups at 14 days following treatment, while the necrotic area of the scar tissue in the shUSP4 and vialinin A (USP inhibitor)-treated animals increased significantly at the 28th and 42nd day compared with the control animals. At days 14, 28 and 42, the expression levels of T $\beta R I$ and Smad7 in the shUSP4 and vialinin A-treated animals were significantly decreased compared with the control animals $(\mathrm{P}<0.05)$. In summary, interference with or inhibition of USP4 prevented the activity of the TGF- $\beta /$ Smad pathway signaling and inhibited the formation of pathological scars.
\end{abstract}

Correspondence to: Dr Zhongyi Cao or Dr Junfeng Yan, Department of Oral and Maxillofacial Surgery, The First Affiliated Hospital of Nanchang University, 17 Yongwai Zheng Street, Nanchang, Jiangxi 330006, P.R. China

E-mail: gaozyyd@163.com

E-mail:66070848@qq.com

Key words: pathological scarring, ubiquitin-specific protease 4, transforming growth factor- $\beta /$ Smad signaling pathway

\section{Introduction}

Scars are the products of wound healing by the human body. Among them, hypertrophic scars (HS) and keloids are known as pathological scars, which are characterized by sustained hyperactive growth, irregular scar shape, and an uneven and tough texture (1). Pathological scars are the result of hypertrophy of scar tissue in the process of tissue repair following trauma. Pathological scars have serious aesthetic effects and result in tissue dysfunction due to deformities of the scar contractures, particularly at the joints. Certain patients experience pain, itching, ulceration and the development of cancerous cells $(2,3)$. Although pathological scars are recognized as harmful, their etiology and pathogenesis are not fully understood.

Ubiquitin-specific protease 4 (USP4), also known as UnpEL or Unph, is encoded by the proto-oncogene USP4. As an important member of the deubiquitinase family, USP4 was initially reported to bind to the tumor suppressor retinoblastoma, and associated pocket proteins retinoblastoma-like protein 1, retinoblastoma-like protein 2 and E3 ubiquitin (4). It has been hypothesized that USP4 and E3 ubiquitin-protein ligase TRIM21 may regulate their substrates by forming heterodimers via ubiquitination/deubiquitination pathways (5). The transforming growth factor- $\beta$ (TGF- $\beta$ ) superfamily members are important functional biological molecules (6). TGF- $\beta$ is closely associated with extracellular matrix deposition, fibrosis and wound healing, which promotes formation of pathological scars (7).

Smads are intracellular molecules of the TGF- $\beta$ signal transduction pathway (8). TGF- $\beta$ activates the pathway through membrane receptors TGF- $\beta$ receptor I (T $\beta R I)$ and T $\beta$ RII, which rapidly phosphorylate Smad proteins activating C-terminal serine residues, forming heterologous complexes that in turn activate the transcription of target nuclear genes $(9,10)$. USP4 has been reported to directly deubiquitylate T $\beta$ RI (11). However, the mechanisms regarding USP4-T $\beta$ RI in pathological scarring are not completely clear. In the present study, the role of USP4 in the formation of pathological scars in BALB/c nude mice inoculated with keloid cells was examined. In addition, the specific molecular mechanism by which USP4 regulates pathological scar formation was assessed. 


\section{Materials and methods}

Construction of a USP4 lentiviral interference vector. Based on data from the National Center for Biotechnology Information, 3 short hairpin RHA (shRNA) sequences were designed by Santa Cruz (Santa Cruz Biotechnology, Inc.) (Table I).

Annealing conditions were as follows: Pre-denaturation at $95^{\circ} \mathrm{C}$ for $5 \mathrm{~min}, 85^{\circ} \mathrm{C}$ for $5 \mathrm{~min}, 75^{\circ} \mathrm{C}$ for $5 \mathrm{~min}$ and $70^{\circ} \mathrm{C}$ for $5 \mathrm{~min}$, and then maintenance at $4^{\circ} \mathrm{C}$. The annealing product (1 $\mu \mathrm{l})$ was diluted 200 -fold and the final concentration was $4.4 \mathrm{ng} / \mathrm{l}$, which was used for subsequent reactions. At $37^{\circ} \mathrm{C}$, a PLVshRNA-EGFP (2A) Puro vector (VL3103; Beijing Yingmao Shengye Biotechnology Co., Ltd.) was digested by Bam H I/EcoRI and subjected to $1 \%$ agarose gel electrophoresis. The 7,861 bp fragments were collected. Lentiviruses encoding shUSP4 were established as described previously (12).

Cell transfection. Human keloid fibroblasts (KFs) were purchased from the American Type Culture Collection (cat. no. CRL-1762) and cultured in Dulbecco's modified Eagle's medium (DMEM; Gibco; Thermo Fisher Scientific, Inc.) supplemented with $10 \%$ fetal bovine serum (FBS; Biological Industries) and $100 \mathrm{U} / \mathrm{ml}$ penicillin-streptomycin (P1400; Beijing Solarbio Science \& Technology, Co., Ltd.) in 5\% $\mathrm{CO}_{2}$ at $37^{\circ} \mathrm{C}$. Cells at $80 \%$ confluence were transfected with the aforementioned lentiviruses (Shanghai GenePharma Co. Ltd.) encoding USP4 shRNA ( $\left.1 \times 10^{6} \mathrm{IFU} / \mathrm{PFU} / \mathrm{ml}\right)$ using Lipofectamine $^{\circledR} 2000$ (Invitrogen; Thermo Fisher Scientific, Inc.). After $6 \mathrm{~h}$, the medium was replaced with fresh DMEM medium containing $10 \% \mathrm{FBS}$ and cells cultured in a $5 \% \mathrm{CO}_{2}$ incubator at $37^{\circ} \mathrm{C}$ for $24 \mathrm{~h}$. Experiments were performed $48 \mathrm{~h}$ after transfection. Expression of USP4 was verified by reverse transcription-quantitative polymerase chain reaction (RT-qPCR). The experimental groups were as follows: Control; shUSP4; vector; vector + TGF- $\beta$ (48 h after transfection, $10 \mathrm{ng} / \mathrm{ml}$ TGF- $\beta$ was applied for an additional $48 \mathrm{~h}$ ); and shUSP4 +TGF- $\beta$ ( $48 \mathrm{~h}$ after transfection, $10 \mathrm{ng} / \mathrm{ml}$ TGF- $\beta$ was applied for an additional $48 \mathrm{~h}$ ).

MTT assay. Following treatment, the cells $\left(3 \times 10^{5} / \mathrm{ml}\right)$ were digested and suspended in 96-well plates. The cell numbers at 0 and $48 \mathrm{~h}$ were assessed by an MTT assay. MTT $(50 \mu \mathrm{l})$ was added to each well, and the cells cultured at $37^{\circ} \mathrm{C}$ for $4 \mathrm{~h}$ in a $5 \% \mathrm{CO}_{2}$ incubator. After $4 \mathrm{~h}$ incubation, supernatants were discarded and dimethyl sulfoxide $(150 \mu \mathrm{l})$ added to each well to dissolve the formazan. Absorption was measured at $550 \mathrm{~nm}$ with an enzyme labeling instrument.

Reverse transcription quantitative polymerase chain reaction $(R T-q P C R)$. Following transfection and treatment for $48 \mathrm{~h}$, mRNA from the different treatment groups was extracted using a TRIzol assay kit (Baosheng Science \& Technology Innovation, Co. Ltd.). mRNA was transcribed into cDNA using a reverse transcription kit (cat. no. 639522, Takara Biotechnology Co., Ltd.) at $37^{\circ} \mathrm{C}$ using the following thermocycler conditions: $25^{\circ} \mathrm{C}$ for $10 \mathrm{~min}, 37^{\circ} \mathrm{C}$ for $120 \mathrm{~min}$ and $85^{\circ} \mathrm{C}$ for $5 \mathrm{~min}$. RT-qPCR was used to detect the expression level of the target genes with SYBR Green (HY-K0501; MedChemExpress). The thermocycling conditions were as follows: Initial denaturation at $95^{\circ} \mathrm{C}$ for $10 \mathrm{~min}$, followed by
40 cycles of PCR at $95^{\circ} \mathrm{C}$ for $10 \mathrm{sec}, 60.3^{\circ} \mathrm{C}$ for $30 \mathrm{sec}$ and $72^{\circ} \mathrm{C}$ for $30 \mathrm{sec}$. The $2^{-\Delta \Delta \mathrm{Ca}}$ method was used to quantify the results as previously described $(13,14)$. The primers $\left(5^{\prime}-3^{\prime}\right)$ used are listed in Table II.

Immunoprecipitation (IP). IP experiments were performed using a Pierce Crosslink IP kit (Thermo Fisher Scientific, Inc.). As described in the manufacturer's instructions, the cells of different groups were homogenized in IP lysis/wash buffer containing proteasome inhibitor MG-132 (10 mM; Sigma-Aldrich; Merck KGaA) and complete EDTA-free Protease Inhibitor Cocktail (Sigma-Aldrich; Merck KGaA). The supernatants were collected after centrifugation at $15,000 \mathrm{x} \mathrm{g}$ for $10 \mathrm{~min}$ at $4^{\circ} \mathrm{C}$. Samples $(2 \mathrm{mg})$ were added to anti-ubiquitin antibody-cross-linked Protein A/G Plus Agarose, and then incubated at $4^{\circ} \mathrm{C}$ overnight. Following incubation, nonspecific binding was eliminated by repeated washing with IP lysis/wash buffer. Eluted IP products were used for western blot analysis to detect ubiquitinated TR $\beta I$ with an anti-Tr $\beta I$ antibody $(1: 1,000$; cat. no. ab92486; Abcam).

Western blot analysis. Following transfection and treatment for $48 \mathrm{~h}$, proteins were extracted from cell lines for western blot analysis using a ReadyPrep protein isolation kit (GE Healthcare Life Sciences) as described previously (15). Protein levels were quantified with a bicinchoninic acid protein assay kit. Proteins ( $25 \mu \mathrm{g} / \mathrm{lane})$ were separated via $12 \%$ SDS-PAGE and transferred onto nitrocellulose membranes. The membranes were blocked with $5 \%$ skim milk for $2 \mathrm{~h}$ at room temperature and incubated with the following primary antibodies overnight at $4^{\circ} \mathrm{C}$ : Anti-TR $\beta \mathrm{I}$ (1:1,000; cat. no. ab92486; Abcam); and anti-Smad7 (1:1,000; cat. no., ab190987; Abcam). The anti-rabbit IgG horseradish peroxidase-conjugated secondary antibody (1:100; cat. no. ab131368; Abcam) was added and incubated with the membranes for $2 \mathrm{~h}$ at room temperature. An enhanced chemiluminescence reagent (cat. no. RPN2133; GE Healthcare Life Sciences) was added to the membranes. The membranes were visualized using a gel imaging system (Bio-Rad Laboratories, Inc.). Densitometry was performed using Quantity One v1.4.6 (Bio-Rad Laboratories, Inc.). Experiments were repeated 3 times.

Establishment of an in vivo tumor model. All animal experiments were approved by the Ethics Committee of Nanchang University (Nanchang, China). A total of 24 male BALB/c nude mice (4-week-old) were purchased from Hunan Shanghai Laboratory Animal Center, Jingda Laboratory Animal Co., Ltd., License No. SCXK 2016-0002) and housed in specific pathogen-free conditions that were automatically maintained at a temperature of $23 \pm 2^{\circ} \mathrm{C}$, a relative humidity of $45-65 \%$, and with a controlled $12 \mathrm{~h} \mathrm{light/dark} \mathrm{cycle.} \mathrm{Mice} \mathrm{implanted} \mathrm{with}$ the tumor cell lines were randomly divided into four groups ( $n=5$ in each group): A control cell group; a control cells + vialinin A (USP inhibitor, HY-13814, MedChemExpress LLC) group; a shUSP4-transfected cell group; and a vector transfected cell group. Animals were injected with KFs in the logarithmic growth phase $\left(1 \times 10^{6}\right)$. For the control group, KFs were diluted in $0.2 \mathrm{ml}$ PBS and administrated through subcutaneous injection into the nude mice. For the vector control 
Table I. shRNA sequences for silencing USP4 expression.

shRNA

molecule
Sequence (5'-3')

$\begin{array}{ll}\text { sh-USP4-F1 } & \text { GATCCGGAAGAAGTATGTGGGCTTTGCTTCCTGTCAGACAAAGCCCACATACTTCTTCCTTTTTG } \\ \text { sh-USP4-R1 } & \text { AATTCAAAAAGGAAGAAGTATGTGGGCTTTGTCTGACAGGAAGCAAAGCCCACATACTTCTTCCG } \\ \text { sh-USP4-F2 } & \text { GATCCGCCTTTCTTCTAGATGGATTGCTTCCTGTCAGACAATCCATCTAGAAGAAAGGCTTTTTG } \\ \text { sh-USP4-R2 } & \text { AATTCAAAAAGCCTTTCTTCTAGATGGATTGTCTGACAGGAAGCAATCCATCTAGAAGAAAGGCG } \\ \text { sh-USP4-F3 } & \text { GATCCGCTGAACATGTCCGAGTTTGTCTTCCTGTCAGAACAAACTCGGACATGTTCAGCTTTTTG } \\ \text { sh-USP4-R3 } & \text { AATTCAAAAAGCTGAACATGTCCGAGTTGTTCTGACAGGAAGACAAACTCGGACATGTTCAGCG }\end{array}$

shRNA, short hairpin RNA; USP4, ubiquitin-specific protease 4; F, forward; R, reverse.

Table II. Primer sequences.

\begin{tabular}{llccc}
\hline Genes & \multicolumn{1}{c}{ Primers } & Primer length, bp & Product length, bp & Annealing temperature, ${ }^{\circ} \mathrm{C}$ \\
\hline T $\beta$ RI F & GACGGCGTTACAGTGTTTCT & 20 & 318 & 56.47 \\
T $\beta$ RI R & CCTTTGCCAATGCTTTCTT & 19 & & 58.82 \\
Smad 7 F & CCAAAGGTCACCACCATCC & 19 & 105 & \\
Smad 7 R & TCAGTTTCTTGAGCACCGAGT & 21 & 224 & 58.3 \\
GAPDH F & GAAGGTCGGAGTCAACGGAT & 20 & & \\
GAPDH R & CCTGGAAGATGGTGATGGG & 19 & & \\
\hline
\end{tabular}

T $\beta$ RI, transforming growth factor- $\beta$ receptor I; F, forward; $R$, reverse.

group, KFs transfected with control vector were diluted in $0.2 \mathrm{ml}$ PBS and injected. For the shUSP4 group, KFs transfected with viral USP4 shRNA were diluted in $0.2 \mathrm{ml}$ PBS and injected. For the control cells + vialinin A group, KFs were treated with vialinin A $(5 \mu \mathrm{M}, 48 \mathrm{~h})$ and diluted in $0.2 \mathrm{ml} \mathrm{PBS}$ and injected. For the shUSP4 group, KFs transfected with viral USP4 shRNA (Santa Cruz Biotechnology, Inc.) were diluted in $0.2 \mathrm{ml}$ PBS and injected. The nude mice were sacrificed at 14, 28 and 42 days after inoculation. All animals presented with a single subcutaneous tumor in the forelimb armpit and the longest diameter was $<8 \mathrm{~mm}$. Following complete anesthesia with $5 \%$ isoflurane, the tumors were excised and stored at $-80^{\circ} \mathrm{C}$ for western blot analysis, RT-qPCR, and fixed with $10 \%$ formalin overnight at $4^{\circ} \mathrm{C}$ for hematoxylin and eosin staining.

Hematoxylin and eosin $(H \& E)$ staining. The tissues were then embedded in paraffin for tissue sectioning and sectioned into $5 \mu \mathrm{m}$-thick sections. Then, the sections were stained with hematoxylin $(3 \%)$ and eosin $(3 \%)$ at room temperature for $3 \mathrm{~min}$ and observed by light microscopy (magnification, $\mathrm{x} 200$, BX51, Olympus Corporation).

Statistical analysis. Data are presented as mean \pm standard error of the mean. Analyses were performed using SPSS version 19.0 (IBM Corp.). Significant differences were determined using one-way analysis of variance followed by the Student-Newman-Keuls post-hoc test. $\mathrm{P}<0.05$ was considered to indicate a statistically significant difference.

\section{Results}

Confirmation of USP4 silencing. As demonstrated in Fig. 1, 3 interference sequences for shUSP4 were designed, with shUSP4-2 producing a significant interference effect. Therefore, shUSP4-2 was selected for subsequent experiments.

shUSP4 decreases cell viability. As presented in Fig. 2, the cell viability of the shUSP4 group was significantly decreased compared with the control group. By contrast, TGF- $\beta$ incubation significantly increased cell viability, which was decreased by shUSP4 interference $(\mathrm{P}<0.05)$. These data suggest that USP4 silencing decreased the proliferation of KFs in the negative control, following TGF- $\beta$-treatment.

shUSP4 decreases T $\beta R I$ and Smad7 expression. The expression levels of T $\beta$ RI and Smad7 for each group are indicated in Fig. 3. Compared with the control group, the expression of T $\beta R I$ and Smad7 by the shUSP4 group was significantly decreased, while the expression levels of T $\beta$ RI and Smad7 in the Vector + TGF- $\beta$ group was significantly increased; this was attenuated by shUSP4 $(\mathrm{P}<0.05)$. As demonstrated by the IP analysis data, ubiquitination of T $\beta$ RI was identified in each group (Fig. 4), indicating a direct correlation of T $\beta$ RI with ubiquitin.

shUSP4 facilitates necrotic death of tumor tissue and decreases the expression of T $\beta R I$ and Smad7. As demonstrated in Fig. 5, at day 14 there was no remarkable difference in the 


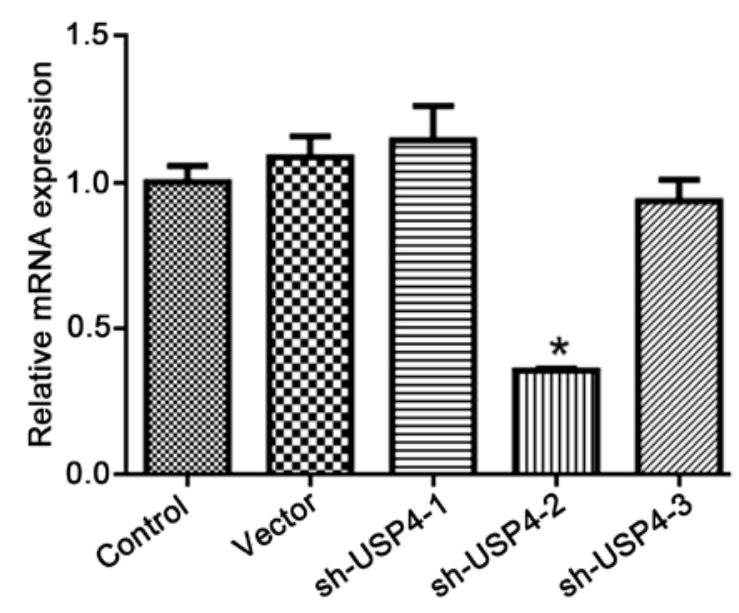

Figure 1 Confirmation of USP4 silencing. The shUSP4-2 sequence significantly decreased USP4 expression compared with the control. " $\mathrm{P}<0.05$. shRNA, short hairpin RNA; USP4, ubiquitin-specific protease 4.

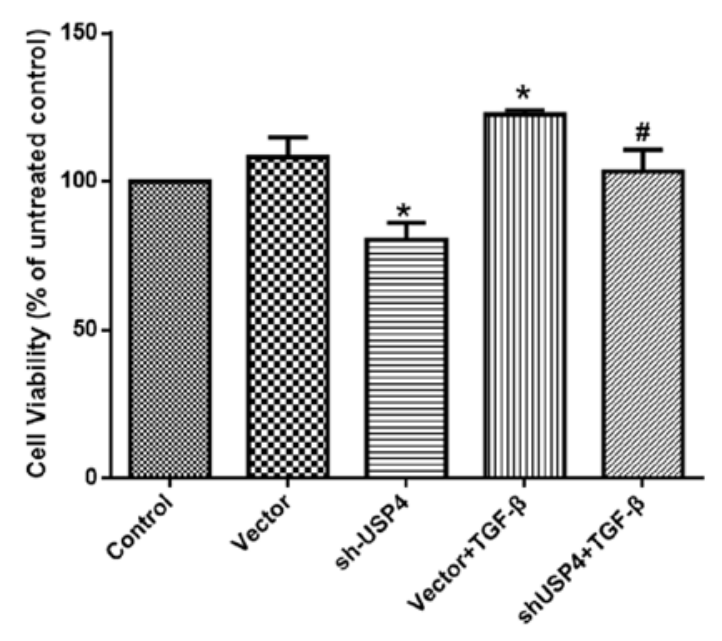

Figure 2. shUSP4 decreases cell viability of control and TGF- $\beta$-treated cells. Following treatment, cells were digested and suspended. Cell viability was detected $48 \mathrm{~h}$ later. USP4 silencing decreased the proliferation of KFs in negative control cells and TGF- $\beta$-treated cells. " $\mathrm{P}<0.05$ vs. control. ${ }^{~} \mathrm{P}<0.05$ vs. vector + TGF- $\beta$. shRNA, short hairpin RNA; USP4, ubiquitin-specific protease 4 .

histological structures of the KF among the groups. At days 28 and 42, marked necrotic scarring was observed in the shUSP4 and vialinin A groups compared with the control group.

As presented in Fig. 6, the expression levels of T $\beta$ RI and Smad7 in the shUSP4 and vialinin A groups were significantly decreased compared with those of the control group at days 14 , 28 and $42(\mathrm{P}<0.05)$.

\section{Discussion}

To the best of our knowledge, the present study is the first to demonstrate that silencing or inhibition of USP4 prevented the TGF- $\beta$ /Smad signaling pathway, which inhibited the formation of pathological scars. USP4 may bind T $\beta$ RI to inhibit the Smad7-mediated signaling pathway, preventing the ubiquitination of T $\beta$ RI, which maintains a high level of T $\beta$ RI and sustained stimulation of TGF- $\beta$ in tissues of the skin.

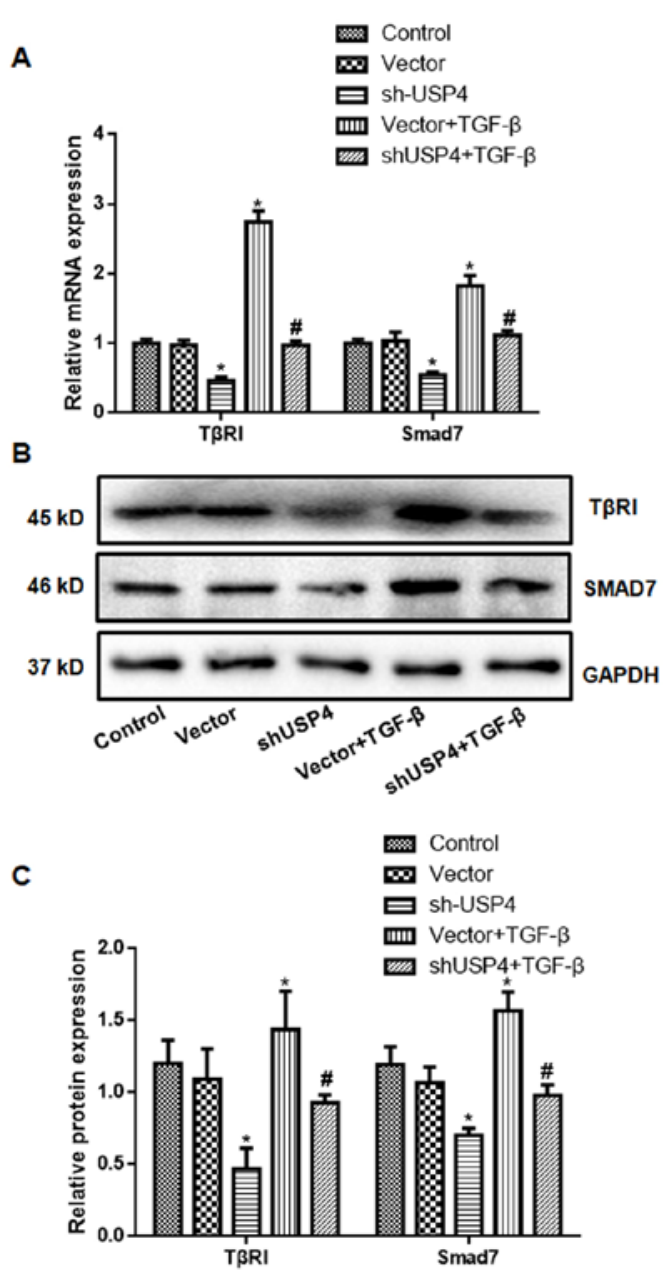

Figure 3. shUSP4 decreases T $\beta R I$ and Smad7 expression. (A) mRNA expression of TRRI and Smad7. (B) Representative blots of T $\beta R I$ and Smad7. (C) Protein expression of T $\beta R I$ and Smad7. ${ }^{*} \mathrm{P}<0.05$ vs. control. ${ }^{*} \mathrm{P}<0.05$ vs. vector + TGF- $\beta$. shRNA, short hairpin RNA; USP4, ubiquitin-specific protease 4 ; T $\beta R I$, transforming growth factor $\beta$ receptor I.

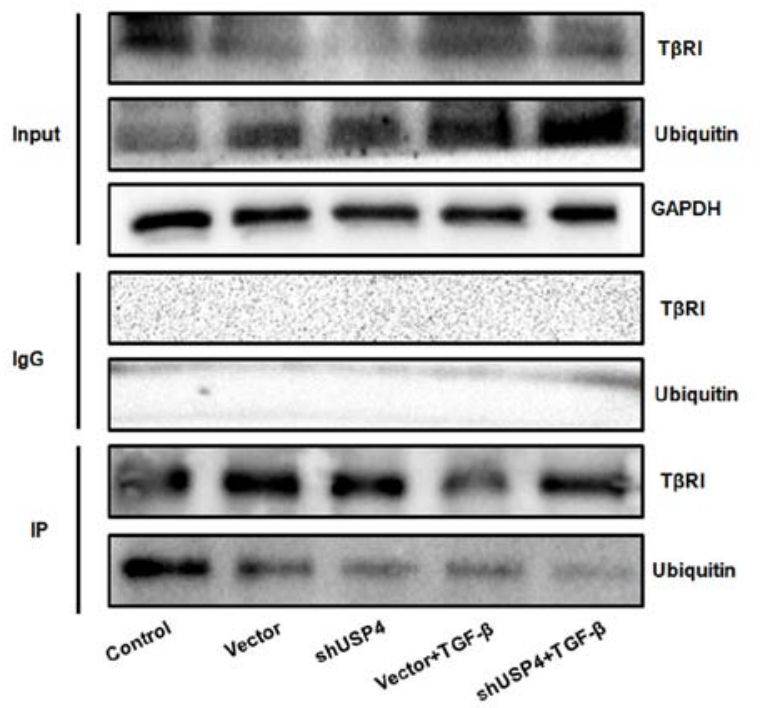

Figure 4. Association between ubiquitin and T $\beta R I$. IP experiments indicated that ubiquitination of T $\beta R I$ was observed in each group, indicating that shUSP4 is likely to affect the levels of T $\beta R I$ ubiquitination. T $\beta R I$, transforming growth factor- $\beta$ receptor I. shRNA, short hairpin RNA; USP4, ubiquitin-specific protease 4; IP, immunoprecipitation. 

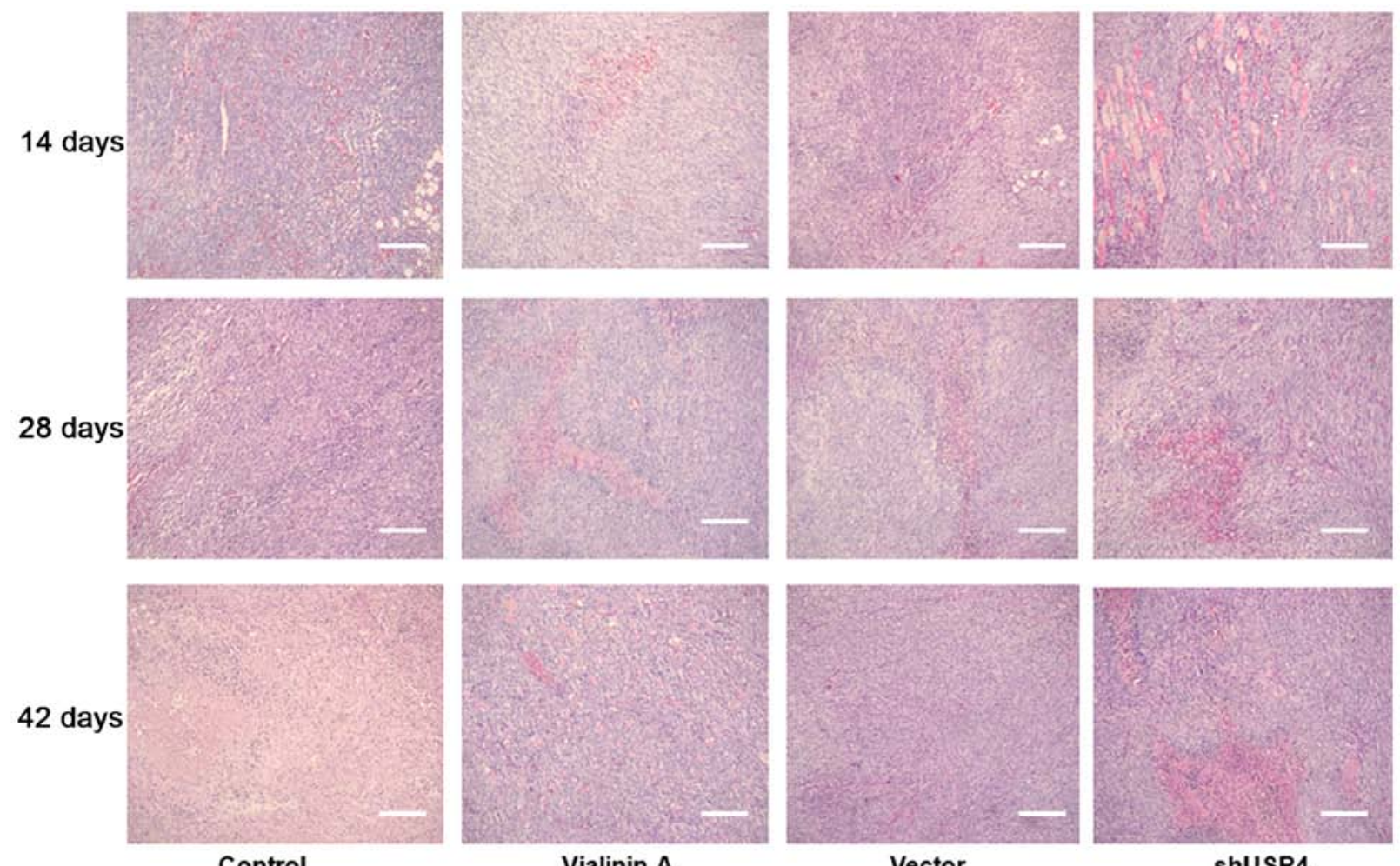

Vialinin A

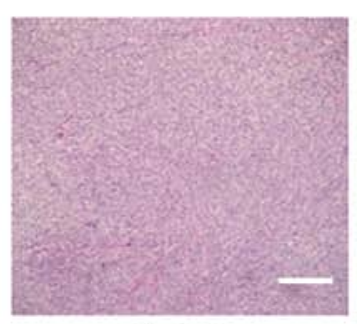

Vector

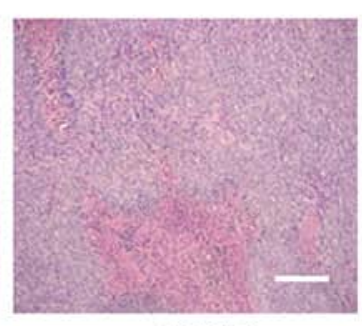

shUSP4

Figure 5. Pathological changes of tumor tissues. There was no significant difference in the histological structure of keloid fibroblasts among the groups at day 14, while the necrotic area of the scars in the shUSP4 and vialinin A groups increased significantly at days 28 and 42 compared with the control group. Scale bars $=100 \mu \mathrm{m}$. shRNA, short hairpin RNA; USP4, ubiquitin-specific protease 4.

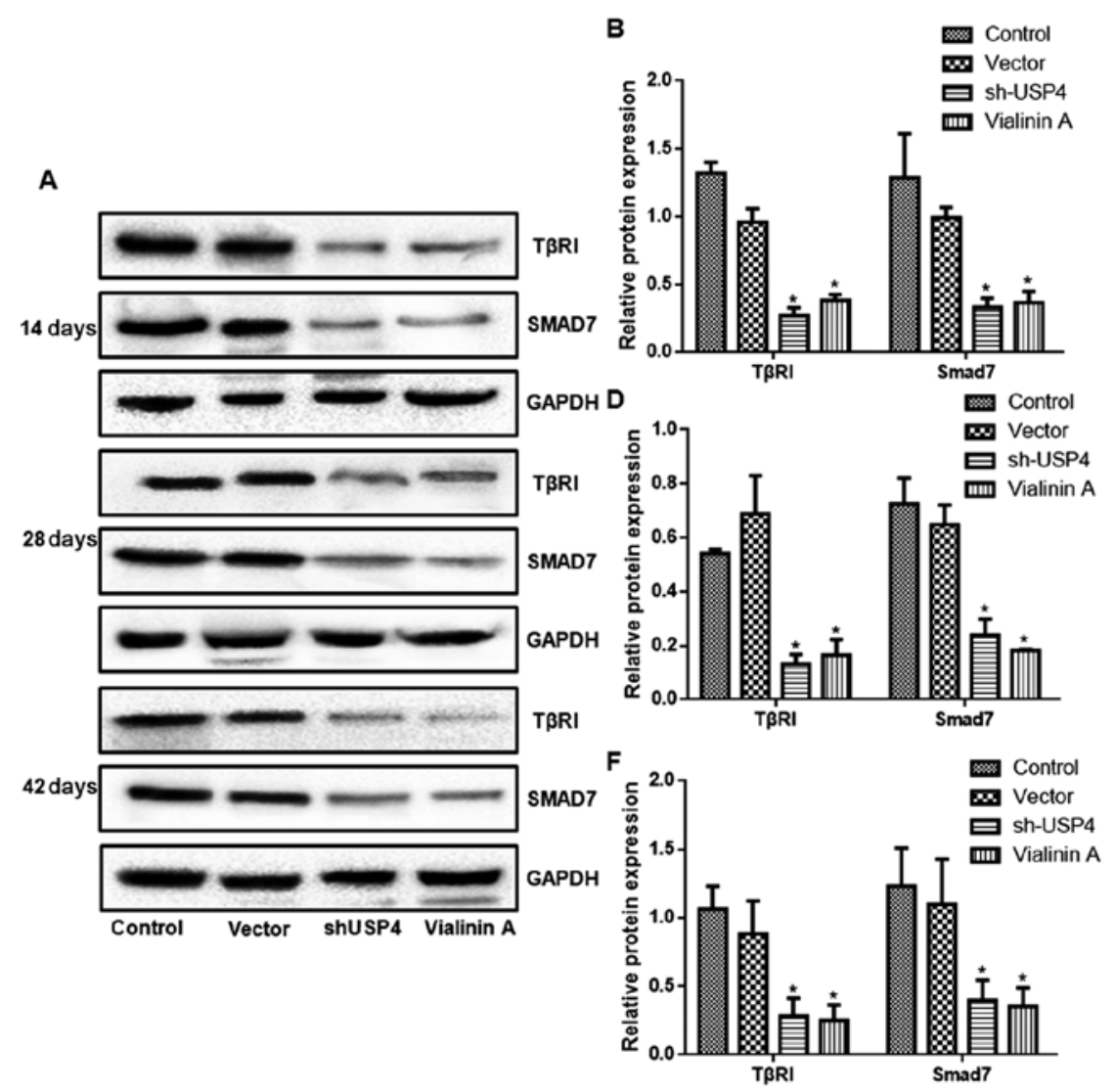

B
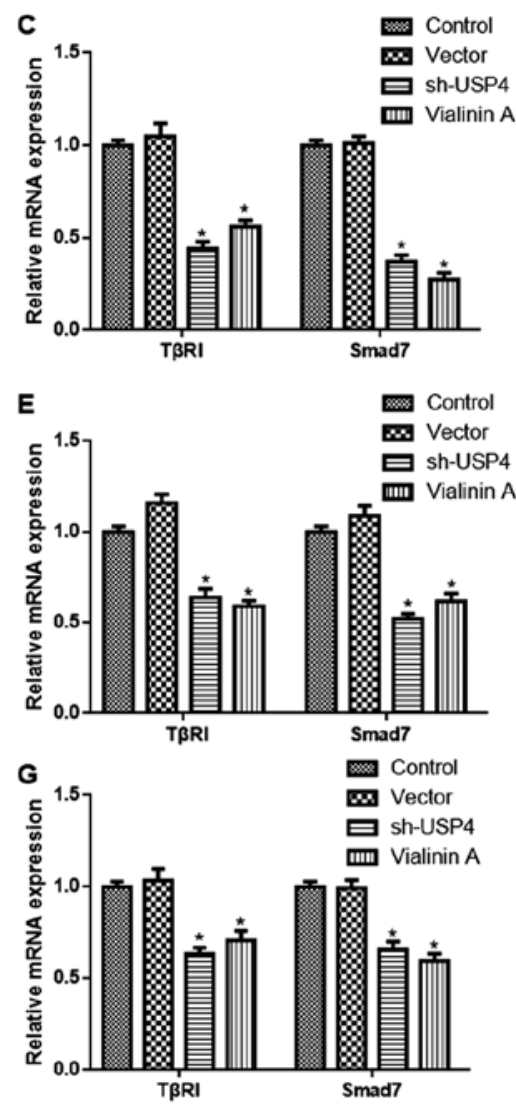

Figure 6. shUSP4 decreases the expression of T $\beta$ RI and Smad7. (A) Representative western blot analysis gel of T $\beta R I$ and Smad7 protein expression. (B) Protein expression of T $\beta R I$ and Smad at day 14. (C) Protein expression of T $\beta R I$ and Smad at day 28. (D) Protein expression of T $\beta R I$ and Smad at day 42. (E) mRNA expression of T $\beta$ RI and Smad at day 14. (F) mRNA expression of T $\beta R I$ and Smad at day 28. (G) mRNA expression of T $\beta R I$ and Smad at day 42 . * P $<0.05$ vs. control. shRNA, short hairpin RNA; USP4, ubiquitin-specific protease 4; T $\beta$ RI, transforming growth factor- $\beta$ receptor I. 
The localization and stability of T $\beta R$ I determines the activity of the TGF- $\beta$ signaling pathway (16), while the Smad7/Smurf 2 complex targets and degrades T $\beta$ RI through the ubiquitination pathway (17). Using genome-wide functional screening, Zhang et al (11) identified that USP4 enhanced the TGF- $\beta$ signaling pathway. USP4 interacts directly with T $\beta$ RI and inhibits its ubiquitination pathway, thereby maintaining a high level of T $\beta$ RI at the cell membrane surface (11). Removal of USP4 attenuates the process of epithelial mesenchymal transition mediated by the TGF- $\beta$ pathway (11). In the present study, cellular and animal experiments revealed that the expression of T $\beta$ RI and Smad7 decreased following USP4 silencing, which indicated that USP4 affected the TGF- $\beta$ signaling pathway. The tumorigenesis experiment demonstrated that USP4 inhibition improved pathological scarring. These results suggested that USP4 may serve a regulatory role in the formation of pathological scars by regulating the TGF- $\beta$ signaling pathway.

USP4 is also involved in the negative regulation of the Wnt signaling pathway (18), deubiquitination of adenosine A2a (19) and regulation of the cell cycle (20). Zhang et al (21) identified that USP4 enhanced its stability by ubiquitinating E3 ubiquitin-protein ligase HUWE1, in turn downregulating P53 expression. Fan et al (22) reported that USP4 downregulated TNF- $\alpha$-induced $N F-\kappa B$ activation by deubiquitinating mitogen-activated protein kinase kinase kinase 7 . In the present study, following the downregulation of USP4, the ubiquitination level of T $\beta$ RI was markedly decreased and pathological scarring improved. These results imply an association between pathological scarring and the ubiquitination level of T $\beta$ RI.

The TGF- $\beta /$ Smad pathway serves a major regulatory role in the formation of pathological scar formation $(23,24)$. The expression of TGF- $\beta 1$, TGF- $\beta 2$ and T $\beta$ RI in keloid keratinocytes was increased compared with that of normal skin, suggesting an association between TGF- $\beta 1$, TGF- $\beta 2$ and T $\beta R I$ in KFs. Fibroblasts have been induced to express more TGF- $\beta 1$ and TGF- $\beta 2$ by paracrine action (25). The expression levels of TGF- $\beta 1 / \mathrm{Smad} 3$ differ during stages of human growth and development; TGF- $\beta / \mathrm{Smad} 3$ are not expressed at all during the fetal period. This may, in part, explain the mechanistic basis for the presence of scarless wounds during the fetal period $(26,27)$. Chin et al $(28)$ demonstrated that the expression levels of T $\beta$ RI and Smad3 proteins in KFs were significantly increased compared with normal skin, indicating that these proteins exhibited positive feedback effects on the TGF- $\beta$ /Smad pathway, promoting the formation of keloids.

Bock et al (29) revealed that in KFs, the expression of T $\beta$ RI was high and the expression of T $\beta$ RII was low, and that the proliferation of KF was enhanced when stimulated with TGF- $\beta 1$. Goldberg et al (30) suggested that the overexpression of T $\beta$ RII inhibited the proliferation of fibroblasts. Bran et al (31) also demonstrated that the expression levels of TGF- $\beta 1$ and TGF- $\beta 2$ in cultured KFs were increased compared with that in normal fibroblasts, while the expression of T $\beta$ RII was significantly decreased compared with that in normal fibroblasts. The TGF- $\beta /$ Smad signal transduction pathway affects the healing process (32). This pathway functions at multiple levels, from the release of early inflammatory mediators, to wound healing, to subsequent pathological scarring (33).
The results of the in vitro and animal experiments suggest that the inhibition of the TGF- $\beta /$ Smad signaling pathway may effectively decrease the deposition of extracellular matrix, and the levels of tissue fibrosis and pathological scarring during wound healing (34). Ubiquitination is a prominent strategy for post-translational modification, which regulates a number of biological functions, including: Cell cycle; apoptosis; DNA damage repair; cellular immunity; and neuronal degeneration (35-37). The results of the present study demonstrate that ubiquitin had a direct association with T $\beta$ RI, which in turn regulated downstream signal transduction and pathological scarring.

There were several limitations of the present study. Firstly, to the best of our knowledge, the study was the first to use an in vivo xenograft tumor model to examine pathological scarring. The similarity between these in vitro and in vivo experiments requires further confirmation. Secondly, whether USP4 may be a target for the treatment of pathological scarring requires additional pharmacological data.

In summary, the inhibition of USP4 attenuates the TGF- $\beta /$ Smad signaling pathway and decreases the formation of pathological scars. The present study provides the foundation for a novel method to prevent and treat pathological scars of the skin.

\section{Acknowledgements}

Not applicable.

\section{Funding}

The present study was supported by the National Natural Science Foundation of China (grant nos. 81460295 and 81660322) and Jiangxi Provincial Science Foundation for Distinguished Young Scholars (grant no. 20171BCB23090).

\section{Availability of data and materials}

The datasets used and/or analyzed during the present study are available from the corresponding author on reasonable request.

\section{Authors' contributions}

JZ, SN, SP, SL, YX, QJ, ZL, JY and ZC performed the experiments and analyzed the data. JZ and ZC designed the study and wrote the manuscript.

\section{Ethics approval and consent to participate}

All animal experiments were approved by the Ethics Committee of Nanchang University (Nanchang, China).

\section{Patient consent for publication}

Not applicable.

\section{Competing interests}

The authors declare that they have no competing interests. 


\section{References}

1. Song H, Tan J, Fu Q, Huang L and Ao M: Comparative efficacy of intralesional triamcinolone acetonide injection during early and static stage of pathological scarring. J Cosmet Dermatol, Jun 22, 2018 (Epub ahead of print).

2. Liao N, Lu F, Zhao W, Zeng WS, Li YT, Wang SJ and Gao JH: Relationship between gene p53 codon 72 polymorphism and pathological scar formation after caesarean section. Zhonghua Zheng Xing Wai Ke Za Zhi 29: 206-210, 2013 (In Chinese).

3. Wu WY, Zhang LT, Zheng ZF, Zhu SZ and Wang ZY: Expression and significance of mRNA and protein of eIF4E, p-eIF4E and MCl-1 in pathological scar. Zhonghua Zheng Xing Wai Ke Za Zhi 28: 360-365, 2012 (In Chinese).

4. DeSalle LM, Latres E, Lin D, Graner E, Montagnoli A, Baker RT, Pagano $\mathrm{M}$ and Loda $\mathrm{M}$ : The de-ubiquitinating enzyme Unp interacts with the retinoblastoma protein. Oncogene 20: 5538-5542, 2001

5. Wada $\mathrm{K}$ and Kamitani T: UnpEL/Usp4 is ubiquitinated by Ro52 and deubiquitinated by itself. Biochem Biophys Res Commun 342: 253-258, 2006.

6. Yan X, Liao H, Cheng M, Shi X, Lin X, Feng XH and Chen YG: Smad7 protein interacts with receptor-regulated Smads (R-Smads) to inhibit transforming growth factor- $\beta$ (TGF- $\beta$ )/Smad signaling. J Biol Chem 291: 382-392, 2016.

7. Dong X, Zhao B, Iacob RE, Zhu J, Koksal AC, Lu C, Engen JR and Springer TA: Force interacts with macromolecular structure in activation of TGF- $\beta$. Nature 542: 55-59, 2017.

8. Sun Q, Guo S, Wang CC, Sun X, Wang D, Xu N, Jin SF and Li KZ: Cross-talk between TGF- $\beta /$ Smad pathway and Wnt/ $\beta$-catenin pathway in pathological scar formation. Int J Clin Exp Pathol 8 : 7631-7639, 2015

9. Beanes SR, Dang C, Soo C and Ting K: Skin repair and scar formation: The central role of TGF-beta. Exp Rev Mol Med 5: 1-22, 2003.

10. Penn JW, Grobbelaar AO and Rolfe KJ: The role of the TGF- $\beta$ family in wound healing, burns and scarring: A review. Int J Burns Trauma 2: 18-28, 2012.

11. Zhang L, Zhou F, Drabsch Y, Gao R, Snaar-Jagalska BE, Mickanin C, Huang H, Sheppard KA, Porter JA, Lu CX and ten Dijke P: USP4 is regulated by AKT phosphorylation and directly deubiquitylates TGF- $\beta$ type I receptor. Nat Cell Biol 14: 717-726, 2012

12. Li W, Tao S, Wu Q, Wu T, Tao R and Fan J: Glutamine reduces myocardial cell apoptosis in a rat model of sepsis by promoting expression of heat shock protein 90. J Surg Res 220: 247-254, 2017.

13. Livak KJ and Schmittgen TD: Analysis of relative gene expression data using real-time quantitative PCR and the 2(-Delta Delta C(T)) method. Methods 25: 402-408, 2001.

14. Zhu G, Li J, He L, Wang X and Hong X: MPTP-induced changes in hippocampal synaptic plasticity and memory are prevented by memantine through the BDNF-TrkB pathway. Br J Pharmacol 172: 2354-2368, 2015.

15. Song Z, Chen H, Xu W, Wu S and Zhu G: Basolateral amygdala calpain is required for extinction of contextual fear-memory. Neurobiol Learn Mem 155: 180-188, 2018.

16. Xiong G, Huang Z, Jiang H, Pan Z, Xie J and Wang S: Inhibition of microRNA-21 decreases the invasiveness of fibroblast-like synoviocytes in rheumatoid arthritis via TGF $\beta /$ Smads signaling pathway. Iran J Basic Med Sci 19: 787-793, 2016.

17. Xu X, Xu C, Saud SM, Lu X, Liu L, Fang L, Zhang X, Hu J and $\mathrm{Li}$ W: Effect of kuijie granule on the expression of TGF- $\beta /$ Smads signaling pathway in patients with ulcerative colitis. Evid Based Complement Alternat Med 2016: 2601830, 2016.

18. Zhao B, Schlesiger C, Masucci MG and Lindsten K: The ubiquitin specific protease 4 (USP4) is a new player in the Wnt signalling pathway. J Cell Mol Med 13: 1886-1895, 2009.

19. Milojevic T, Reiterer V, Stefan E, Korkhov VM, Dorostkar MM, Ducza E, Ogris E, Boehm S, Freissmuth M and Nanoff C: The ubiquitin-specific protease Usp4 regulates the cell surface level of the A2A receptor. Mol Pharmacol 69: 1083-1094, 2006.
20. Wijnhoven P, Konietzny R, Blackford AN, Travers J, Kessler BM, Nishi R and Jackson SP: USP4 auto-deubiquitylation promotes homologous recombination. Mol Cell 60: 362-373, 2015.

21. Zhang X, Berger FG, Yang J and Lu X: USP4 inhibits p53 through deubiquitinating and stabilizing ARF-BP1. EMBO J 30: 2177-2189, 2011.

22. Fan YH, Yu Y, Mao RF, Tan XJ, Xu GF, Zhang H, Lu XB, Fu SB and Yang J: USP4 targets TAK1 to downregulate TNFo-induced NF- $\kappa B$ activation. Cell Death Differ 18: 1547-1560, 2011.

23. Wang Y, Zhang L, Lei R, Shen Y, Shen H, Wu Z and Xu J: Effects of blocking two sites of transforming growth factor- $\beta /$ Smads signaling on the formation of scar-related proteins in human skin fibroblasts. Zhonghua Shao Shang Za Zhi 31: 372-377, 2015 (In Chinese).

24. Nong Q, Li S, Wu Y and Liu D: LncRNA COL1A2-AS1 inhibits the scar fibroblasts proliferation via regulating $\mathrm{miR}-21 / \mathrm{Smad} 7$ pathway. Biochem Biophys Res Commun 495: 319-324, 2018.

25. Xia W, Phan TT, Lim IJ, Longaker MT and Yang GP: Complex epithelial-mesenchymal interactions modulate transforming growth factor-beta expression in keloid-derived cells. Wound Repair Regen 12: 546-556, 2004.

26. Emami A, Halim AS, Salahshourifar I, Yussof SJ, Khoo TL and Kannan TP: Association of TGF 31 and SMAD4 variants in the etiology of keloid scar in the Malay population. Arch Dermatol Res 304: 541-547, 2012

27. Ward SV, Cadby G, Heyworth JS, Fear MW, Wallace HJ, Cole JM, Wood FM and Palmer LJ: Association of TGFß1 and clinical factors with scar outcome following melanoma excision. Arch Dermatol Res 304: 343-351, 2012.

28. Chin GS, Liu W, Peled Z, Lee TY, Steinbrech DS, Hsu M and Longaker MT: Differential expression of transforming growth factor-beta receptors I and II and activation of Smad 3 in keloid fibroblasts. Plast Reconstr Surg 108: 423-429, 2001.

29. Bock O, Yu H, Zitron S, Bayat A, Ferguson MW and Mrowietz U: Studies of transforming growth factors beta 1-3 and their receptors I and II in fibroblast of keloids and hypertrophic scars. Acta Derm Venereol 85: 216-220, 2005.

30. Goldberg HJ, Huszár T, Mózes MM, Rosivall L and Mucsi I: Overexpression of the type II transforming growth factor-beta receptor inhibits fibroblasts proliferation and activates extracellular signal regulated kinase and c-Jun $\mathrm{N}$-terminal kinase. Cell Biol Int 26: 165-174, 2002.

31. Bran GM, Goessler UR, Schardt C, Hormann K, Riedel F and Sadick H: Effect of the abrogation of TGF-beta1 by antisense oligonucleotides on the expression of TGF-beta-isoforms and their receptors I and II in isolated fibroblasts from keloid scars. Int J Mol Med 25: 915-921, 2010.

32. Li SC, Ma LN, Chen J and Li YK: Effect of allicin on myocardial fibrosis after myocardial infarction in rats and its relationship with TGF $\beta /$ Smads signal transduction. Zhongguo Zhong Yao Za Zhi 41: 2517-2521, 2016 (In Chinese).

33. Hu ZC, Shi F, Liu P, Zhang J, Guo D, Cao XL, Chen CF, Qu SQ, Zhu JY and Tang B: TIEG1 Represses Smad7-mediated activation of TGF- $\beta 1 /$ Smad signaling in keloid pathogenesis. J Invest Dermatol 137: 1051-1059, 2017.

34. D'Arpino MC, Fuchs AG, Sánchez SS and Honoré SM: Extracellular matrix remodeling and TGF- $\beta 1 /$ Smad signaling in diabetic colon mucosa. Cell Biol Int 42: 443-456, 2018.

35. Popovic D, Vucic D and Dikic I: Ubiquitination in disease pathogenesis and treatment. Nat Med 20: 1242-1253, 2014.

36. Wu Y, Kang J, Zhang L, Liang Z, Tang X, Yan Y, Qian H, Zhang $\mathrm{X}, \mathrm{Xu} \mathrm{W}$ and Mao F: Ubiquitination regulation of inflammatory responses through NF- $\kappa$ B pathway. Am J Transl Res 10: 881-891, 2018.

37. Cheng YF, Zhu GQ, Wang M, Cheng H, Zhou A, Wang N, Fang N, Wang XC, Xiao XQ, Chen ZW and Li QL: Involvement of ubiquitin proteasome system in protective mechanisms of Puerarin to MPP(+)-elicited apoptosis. Neurosci Res 63: 52-58, 2009. 